\title{
Modal Analysis of Worm and Worm Gear Based on ANSYS Workbench
}

\author{
Yichang Liu ${ }^{1, a}$, Chunlin Tian ${ }^{1}$, Tao Liu ${ }^{1}$ and Fanwu Kong ${ }^{2}$ \\ ${ }^{1}$ Changchun University of Science and Technology, Changchun, Jilin, China \\ ${ }^{2}$ Jinlin Northeast Industrial Group, Changchun, Jilin, China
}

\begin{abstract}
To establish the three-dimensional model of the worm and worm gear by using SolidWorks. On the worm and worm gear modal analysis is carried out by using finite element analysis software ANSYS Workbench. Obtain the first 6 order natural frequency and vibration mode characteristics of worm and worm gear. Modal analysis laid the foundation for further study on dynamics analysis, Also for the worm and worm gear structure optimization design provides a reference.
\end{abstract}

\section{Introduction}

Worm and worm gear mechanism used to transmit motion and power between the two crossed axis, high transmission ratio can be achieved, and also can achieve self locking ${ }^{[1]}$. The research object of this paper is a pair of ordinary cylindrical worm and worm gear which is applied in automobile automatic clutch. Due to Vibration will cause structural resonance or fatigue, lead to damage of the clutch structure, for the worm and worm gear are easy to produce resonance problems, to prevent the resonance, modal analysis is necessary for the worm and worm gear.

ANSYS Workbench is a new generation product development platform, which is a large scale general finite element analysis software with structure, fluid, electric field, magnetic field, sound field analysis, with CAD seamless interface, Parametric modeling tools of a new generation, achieved data share and exchange, its powerful analysis function can accurately reflect the actual object state ${ }^{[2]}$.

\section{The establishment of the model}

\subsection{Establishment of SolidWorks 3D model}

The main parameters of worm and worm gear as below: for the worm, number of head $Z_{1}=1$, modulus $\mathrm{m}_{\mathrm{a} 1}=1.25 \mathrm{~mm}$, pitch circle diameter $\mathrm{d}_{1}=11.53 \mathrm{~mm}$, tooth profile angle $\mathrm{aa}_{1}=20^{\circ}$, pitch angle of lead $\mathrm{r}=7.02^{\circ}$, the length of worm helical $\mathrm{L}=49.5 \mathrm{~mm}$; for the worm gear, the number of teeth $\mathrm{Z}_{2}=60$, modulus $\mathrm{m}_{\mathrm{t} 2}=1.25 \mathrm{~mm}$, pitch circle diameter $\mathrm{d}_{2}=76.25 \mathrm{~mm}$, pressure angle $\mathrm{a}_{\mathrm{t} 2}=20^{\circ}$.

\subsection{Establishment of Finite Element Model}

As the new interface of ANSYS, ANSYS Workbench can achieve seamless connection with CAD system, it is very convenient to make the CAD model import into the ANSYS Workbench ${ }^{[3]}$.The worm and worm gear model is saved as STP format file, And then imported to the ANSYS Workbench Geometry, before modal analysis, first of all, to set the material and its properties, in this paper, the material of worm is No.45 steel, density $\rho_{1}=7.85 \mathrm{~g} / \mathrm{cm} 3$, modulus of elasticity $E_{1}=209 \mathrm{GPa}$, Poisson's ratio $\mu_{1}=0.269$; the material of worm gear is POM, density $\rho_{2}=1.39 \mathrm{~g} / \mathrm{cm} 3$, modulus of elasticity $\mathrm{E}_{2}=2.6 \mathrm{GPa}$, Poisson's ratio $\mu_{2}=0.38569$. After the

\footnotetext{
${ }^{a}$ Corresponding author: 705439344@qq.com
} 
material setup is finished, go to the modal module for Preprocessing operation, considering the complex modeling and solving speed, in this paper, the grid division are used Automatic Method, the element size is set to $2 \mathrm{~mm}$, the number of nodes for the worm is 33963 , the number of elements for the worm is 20416; the number of nodes for the worm gear is 87216 , the number of elements for the worm is 53349, the finite element model of the worm and worm gear are shown in fig. 1.

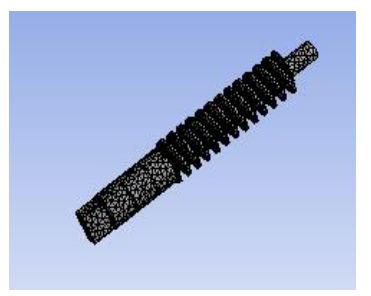

Worm

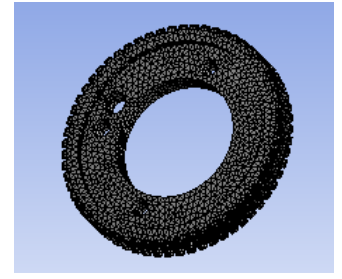

Worm gear
Fig. 1.The finite element model of the worm and worm gear

\section{The Constraint Conditions}

Using different constraints will have a direct impact on the results of the analysis, different constraint conditions, the modal parameters obtained are also different ${ }^{[4]}$. For the worm, it can only around its own axis ( $Z$ axis) rotation, therefore, to restrict the worm around $\mathrm{X}, \mathrm{Y}$ axis rotation and move along the $\mathrm{X}, \mathrm{Y}, \mathrm{Z}$ axis; for the worm gear, also it can only around its own axis ( $\mathrm{Z}$ axis) rotation, limit the other direction freedom. In the modal: for the worm, add Cylindrical Support, and the Tangential is set to Free, and add the Displacement constraint in the worm one side end face, restrictions on the movement of the axial; for the worm gear, add the Fix Support in its rotation center, limit its around $\mathrm{X}, \mathrm{Y}$ axis of rotation and movement, and add the Displacement constraint on the worm gear end surface, limit the movement along the $\mathrm{Z}$ axis.

\section{Modal analysis of worm and worm gear}

\subsection{Overview of Modal Analysis}

Modal analysis is a numerical technique to calculate the vibration characteristics of structure, the structure vibration characteristics including natural frequency and vibration mode. Modal analysis is the basic of dynamics analysis, also is the foundation of other dynamics analysis, such as the response spectrum analysis, random vibration analysis and the harmonic response analysis. Modal analysis can make structure design to avoid the resonance, help to solve the control parameter in other dynamic analysis ${ }^{[5]}$.

\subsection{The Basic of Modal Analysis}

No damping modal analysis is a classical eigenvalue problem. The basic equation of dynamics problems is:

$$
[M]\{\ddot{x}(t)\}+[K]\{x(t)\}=0
$$

In the equation(1): $[M]$--mass matrix; $[K]$--stiffness; $\ddot{x}(t)$--acceleration vector; $\mathrm{x}(t)$--the displacement vector

Free vibration of structure is simple harmonic vibration, the displacement as a sinusoidal function.

$$
x=x \sin (w t)
$$

Substitute equation(2) into equation(1):

$$
([K]-w[M])\{x\}=0
$$

Equation(2) is the classical eigenvalue problem, characteristic value of this equation is $w_{i}{ }^{2}$ 错误! 未找到 引用源。, self vibration frequency is $f=\frac{w_{i}}{2 \pi}$ 错误! 未 找到引用源。， the eigenvalues错误！未找到引用源。 correspond eigenvectors $x_{i}$ are the natural frequency $f=\frac{w_{i}}{2 \pi}$ 错误！未找到引用源。correspond vibration type ${ }^{[6]}$.

\subsection{The Result of Modal Analysis}

Obtained the worm and worm gear the first 6 order natural frequency and vibration type in this paper, the natural frequency and vibration type description are shown in table 1 ,table 2 . The first 6 order modal shape of worm and worm gear are shown in fig. 2 . 


\begin{tabular}{|c|c|c|c|c|c|c|}
\hline Order & 1 & 2 & 3 & 4 & 5 & 6 \\
\hline Frequency[f/Hz] & 8605.3 & 10032 & 10140 & 18088 & 24663 & 24873 \\
\hline $\begin{array}{c}\text { Vibration type } \\
\text { description }\end{array}$ & $\begin{array}{c}\text { The first } \\
\text { torsion }\end{array}$ & $\begin{array}{c}\mathrm{X} \text { axis the first } \\
\text { order bending }\end{array}$ & $\begin{array}{c}\text { Y axis the first } \\
\text { order bending }\end{array}$ & $\begin{array}{c}\text { The second } \\
\text { torsion }\end{array}$ & $\begin{array}{c}\mathrm{X} \text { axis the second } \\
\text { order bending }\end{array}$ & $\begin{array}{c}\text { Y axis the second } \\
\text { order bending }\end{array}$ \\
\hline
\end{tabular}

Table 1. The first 6 order natural frequency and vibration type description of worm

Table 2. The first 6 order natural frequency and vibration type description of worm gear

\begin{tabular}{|c|c|c|c|c|c|c|}
\hline Order & 1 & 2 & 3 & 4 & 5 & 6 \\
\hline Frequency[f/Hz] & 6903.3 & 8674.9 & 8693.4 & 11508 & 11822 & 12639 \\
\hline $\begin{array}{c}\text { Vibration type } \\
\text { description }\end{array}$ & $\begin{array}{c}\text { The first } \\
\text { torsion }\end{array}$ & $\begin{array}{c}\text { The second } \\
\text { torsion }\end{array}$ & $\begin{array}{c}\text { The third } \\
\text { torsion }\end{array}$ & $\begin{array}{c}\text { The first } \\
\text { bending }\end{array}$ & $\begin{array}{c}\text { The second } \\
\text { bending }\end{array}$ & The third bending \\
\hline
\end{tabular}

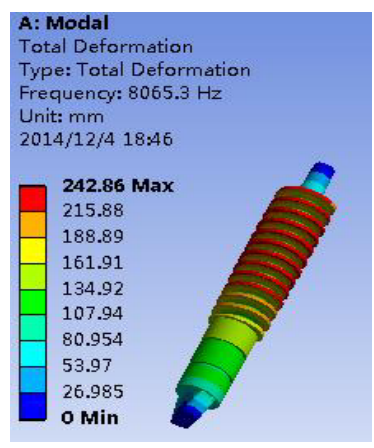

Worm first order modal

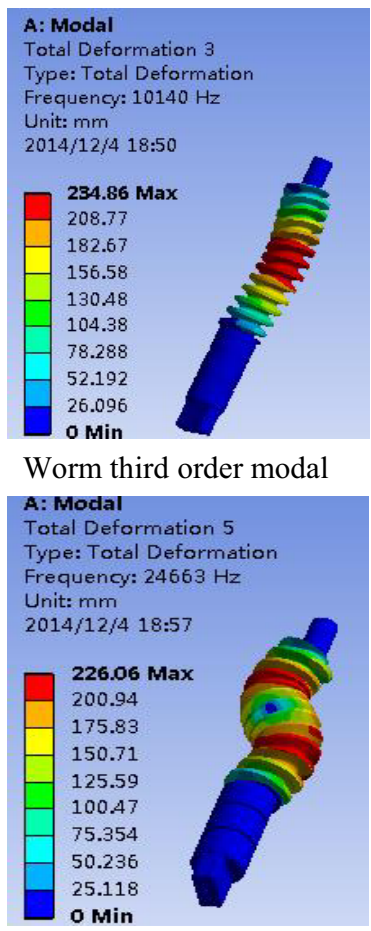

Worm fifth order modal

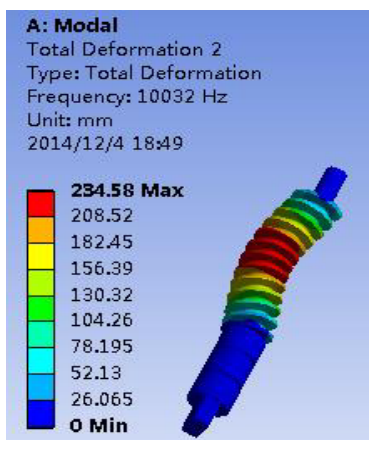

Worm second order modal

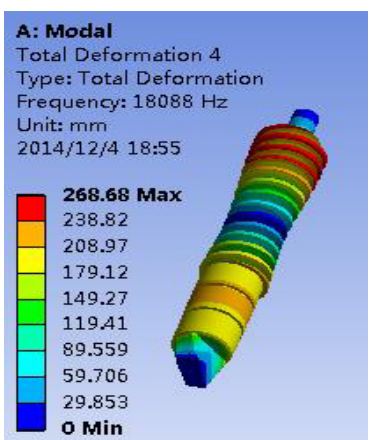

Worm forth order modal

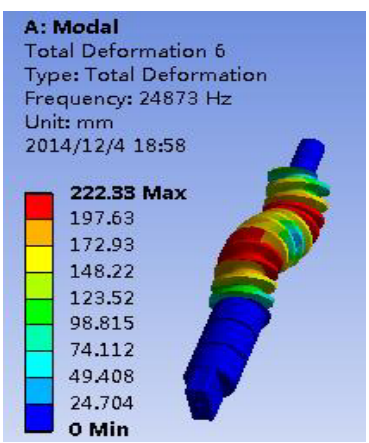

Worm sixthorder modal

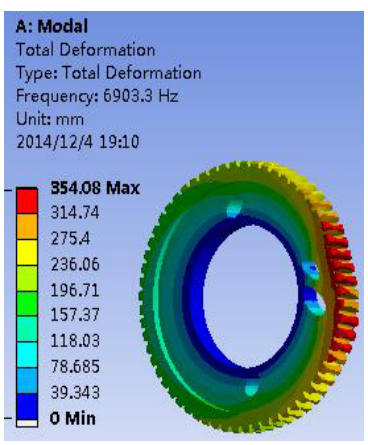

Worm gear first order modal

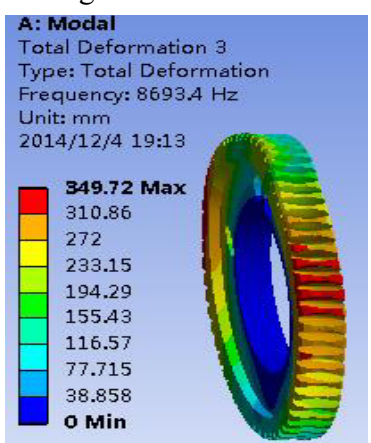

Worm gear third order modal

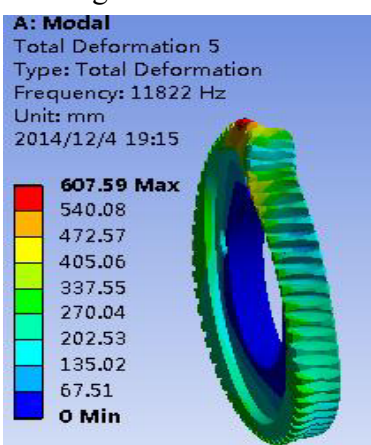

Worm gear fifth order modal

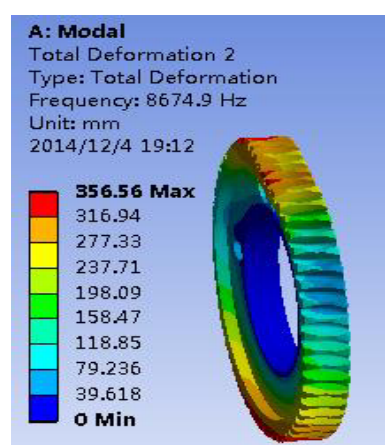

Worm gear second order modal

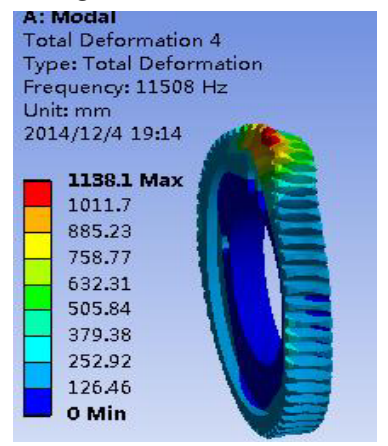

Worm gear forth order modal

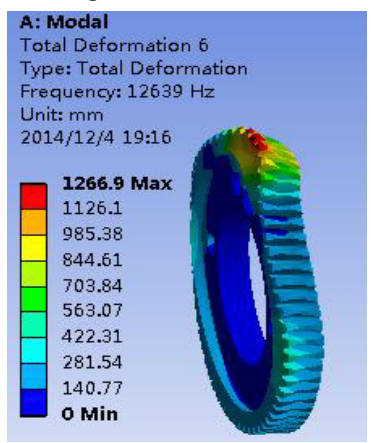

Worm gear sixth order modal

Fig. 2. the first 6 order modal vibration modal graph of worm and worm gear

\section{Conclusion}


For accurate modeling of the worm and worm gear by using SolidWorks, the model imported into ANSYS Workbench, the model was meshed and added constraints, to obtain the first 6 order natural frequency and vibration mode, and the vibration modes are described. The results

\section{Reference}

1. Lianggui $\mathrm{P}$, Minggang J: Mechanical design,238 (2006)

2. Zhixin H,Chengzhu L: ANSYS Workbench14.0 super learning manual, 3-17 (2013)

3. Li L, Mingqi N: Process and technology.12, 107 (2011) of this analysis for the following dynamic analysis and structure optimization design provides an important basis, also laid the foundation for more in-depth study on the vibration and noise problems, to provide a reference and basis for the practical experiment.

4. Duan L, Dongjian Z, Xiaoyang Y and Longping Z: Machinery design and Manufacture, 8,12 (2012)

5. Zhixin H,Chengzhu L: ANSYS Workbench14.0 super learning manual, 214-216 (2013)

6. Zhixin H,Chengzhu L: ANSYS Workbench14.0 super learning manual, 215-216 (2013) 